\title{
Optimization Model for School Transportation Based on Supply-Demand Analyses
}

\author{
Jairo Ortega1, János Tóth1, Juan Palaguachi2, Imad Sabbani³ \\ ${ }^{1}$ Department of Transport Technology and Economics, Budapest University of Technology and Economics, Budapest, Hungary \\ ${ }^{2}$ Department of Transportation, Escuela Superior Politécnica of Chimborazo, Riobamba, Ecuador \\ ${ }^{3}$ Department of Sciences and Techniques, University of Hassan II and Franche-Comté University, Besançon, France \\ Email: ortega.jairo@mail.bme.hu, toth.janos@mail.bme.hu, juan.palaguachi@espoch.edu.ec,imadsabbani@gmail.com
}

How to cite this paper: Ortega, J., Tóth, J., Palaguachi, J. and Sabbani, I. (2019) Optimization Model for School Transportation Based on Supply-Demand Analyses. Journal of Software Engineering and Applications, 12, 215-225.

https://doi.org/10.4236/jsea.2019.126013

Received: May 2, 2019

Accepted: June 25, 2019

Published: June 28, 2019

Copyright $\odot 2019$ by author(s) and Scientific Research Publishing Inc. This work is licensed under the Creative Commons Attribution International License (CC BY 4.0).

http://creativecommons.org/licenses/by/4.0/

\section{(c) (i) Open Access}

\begin{abstract}
This paper presents a new conception model of school transportation supply-demand ratio (STSDR) in order to define the number of school buses needed in a limited area and to describe the conditions of school transport system. For this purpose, a mathematical equation was elaborated to simulate the real system based on the school transport conditions and on the estimated results of STSDR from 15 zones of Cuenca city in Ecuador. The data used in our model was collected from several diverse sources (i.e. administrative data and survey data). The estimated results have shown that our equation has described efficiently the school transport system by reaching an accuracy of $96 \%$. Therefore, our model is suitable for statistical estimation given adequate data and will be useful in school transport planning policy. Given that, it is a support model for making decisions which seek efficiency in supply and demand balance.
\end{abstract}

\section{Keywords}

School Transport, Model Optimization, Supply-Demand, Travel to School

\section{Introduction}

School transportation is the process of generating a set of school buses that efficiently transports students to and from their schools safely and on time. Meanwhile, school travel is short journey reliably made for several students together. Therefore, school transportation and School travel are vital for policy decisions 
which may have a substantial impact on school district funding, student safety, and student access to different schools. However, the school bus transportation has been traditionally viewed as secondary or even tertiary concerns relative to mobility impacts by the governments and authorities across the globe. The relative lack of academic and policy attention in this area merits nowadays more implications in policy, planning and projects.

Recently some researchers have focused on optimizing school transport from different viewpoints in literature i.e. demand analysis [1] school transport time [2] supply transport [3] number of students [4] number of seats [5] number of vehicles [6], and so on. For example in [7], authors have described and evaluated a practical computer-based method for translating data concerning 1) the location of each school 2) the location of each student, 3) the time, and 4) the available buses. Other authors have proposed [8] a multi-objective problem, for which there are 71 possible optimal options, which minimize school transport cost between $2.7 \%$ and $35.1 \%$ regarding current school transport routes, with different school start time and minimum travel time for students. [9] has developed an estimation model of urban transportation supply-demand ratio (TSDR) to quantitatively describe the conditions of an urban transport system and to support a theoretical basis for transport policy-making. According to authors, the estimated results indicate that an urban TSDR can be classified into four grades representing four transport conditions: "scarce supply", "short supply", "supply-demand balance" and "excess supply".

The purpose of this paper is to propose a new conception model of school transportation supply-demand ratio (STSDR) in order to describe the conditions of school transport system and to support theoretical and mathematical basis for transport policy-making. Based on these, this paper is organized as follows. Section II details our data used in our model. Section 3 describes the area of this study and presents results of STSDR from 15 zones of Cuenca city in Ecuador. Concluding and discussion are given in Section 4.

\section{Data and Research Design}

Our school transportation supply-demand database is mainly based on linkage between administrative and survey data in order to create more comprehensive and effective datasets for analyses. Linking survey and administrative information offered many advantages and huge potential for our policy-related research, by combining administrative data from Municipality of Cuenca city database, which contains information on school transport conditions, with two detailed surveys data with the purpose to determine the lack of administrative data and to enhance the limited set of information recorded. As seen in Figure 1, our linked data set contains many variables (i.e. number of students, number of buses, number of schools, modal split and bus occupancy) providing an optimal data source for defining the number of buses needed within each zone in Cuenca city by applying the supply-demand model. 
ADMINISTRATIVE DATA

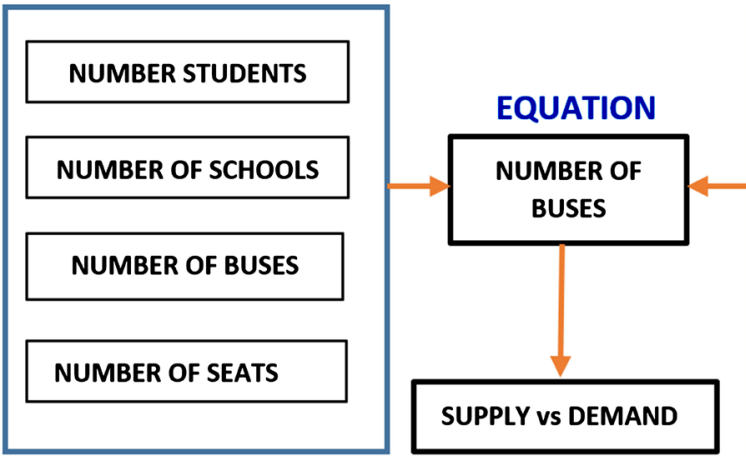

Figure 1. Linked administrative and survey data.

\subsection{Administrative Data}

Administrative-data is a source of large and complex quantitative information which derive from operation of administrative systems, typically by government departments and other organization for the purpose of registration, transaction and record keeping [10]. These datasets have been used to produce official statistics to inform policymaking. The potential for this data to be accessed for the purposes of social science research is increasingly recognized, although as yet has not been fully exploited. In our case, administrative-data is collected using data from the following sources:

- School Ministry-2016

- Mobility Plan 2015-2017

School Ministry data was provided by the Education Government and contains information about the number of students and location of schools per zone (Z), using all transports modes bus, taxi, private vehicle and their combinations, which represent the future-demand in our model. On the other hand, the Mobility Plan 2015-2017 provided us the total number of buses (417) and their dispatching per zone, which represent supply. Figure 2 shows the geographical distribution of students in Cuenca city in comparison with the number of buses dedicated per zone.

Our aim is to analyze the relationship between the number of students and the number of dispatched school-buses. Particularly we attempt to determine the minimum number of dispatched buses in each zone. As seen in Figure 2, the dispatching of buses does not reflect the repartition of students in some zones of Cuenca city. For example, in zones 2, 4, 8, 12 and 13 we have high density of students with few buses. However, in zones 11, 15, 5 and 7 we have a low density of students with few school-buses, and the zones 1, 3, 10 and 14 have high density of students with high concentration of buses. We can understand by this Figure that having a high student's population density may not guarantee more students to use school-transport. For this reason, to identify the most important qualitative factors affecting this non-linear repartition of the school transportation system and to determine the factors that substantially influence the students' decisions, a questionnaire survey is conducted in order to complete administrative-data. 


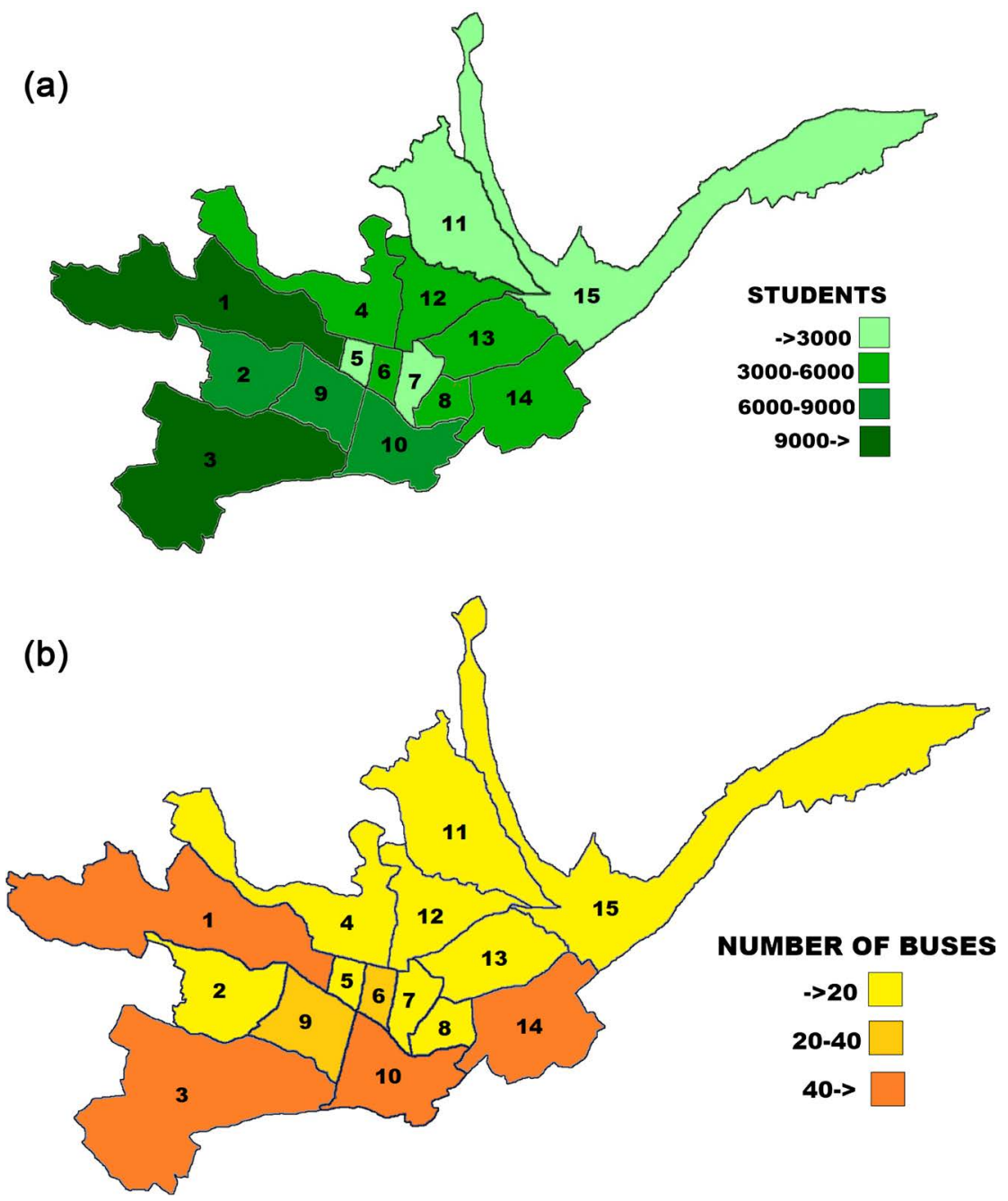

Figure 2. (a) Students, (b) number of buses.

\subsection{Survey Data}

Survey data has become one of the most important sources of information for policymakers and source of data with great potential for forecasting social and economic topics. This method allowed us to produce certain statistical measures in a relatively short period. More recently, researchers have tended to link survey data with administrative records [11] [12], in order to collect the necessary data that cannot be obtained by the administrative data, and the ability to drive the design, rather than being limited to existing data. In this study, we elaborated two surveys based on supply and demand with the purpose to define the student's preferences and the buses occupancy.

\subsubsection{Demand Approach}

The first survey was to collect data about students and their trips. We conducted our survey in Cuenca city during June 2016 by intercepting students on the schools based on their locations provided by our administrative data. Our survey consists of 20 questions regarding their trip origin and destination, previous and 
alternative modal choice, car ownership, and basic demographics. We used a level of confidence around $95 \%$ and margin mistake 5\%. According to the design of the sample, it is appropriate to apply this expansion factor to each selected student, which depends on the number of students, in our case 75.574. According to the equation of the sample size, we had to survey 4929 students. The expansion factors include a population adjustment, according to the projections to the date of the survey, in order to increase the precision of the estimates. Table 1 shows a summary of the student's travel mode choice after completion of our survey in each zone, which represents one of the most influence factors in politic-maker decision. We can distinguish that walking to school, using public or private transport are the most frequent in Cuenca city. The school transport is restricted in less than $20 \%$ in majority of zones. Public Transport and private vehicle are clearly the two primary modes chosen for school trips. Non-motorized modes (pedestrian and bicycle) accounted for less than $25 \%$ of all school trips. Travel by contracted taxi about $1 \%$ of the trips as shown in Table 1.

The declared preference of Cuenca city students is shown in Table 2 . We can understand from Table 2, that we have an equitable repartition of around $50 \%$

Table 1. Model split school transportation of Cuenca city.

\begin{tabular}{cccccccc}
\hline ZONE & PUBLIC T & TAXI & SCHOOL T. & PICK UP & PRIVATE & BYCYCLE & WALK \\
\hline $\mathbf{1}$ & $34.76 \%$ & $0.56 \%$ & $10.72 \%$ & $0.38 \%$ & $28.80 \%$ & $1.30 \%$ & $23.49 \%$ \\
$\mathbf{2}$ & $29.81 \%$ & $1.92 \%$ & $4.81 \%$ & $0.00 \%$ & $31.09 \%$ & $1.00 \%$ & $31.37 \%$ \\
$\mathbf{3}$ & $35.38 \%$ & $3.06 \%$ & $7.24 \%$ & $0.84 \%$ & $24.23 \%$ & $1.11 \%$ & $28.13 \%$ \\
$\mathbf{4}$ & $32.97 \%$ & $5.90 \%$ & $14.43 \%$ & $1.63 \%$ & $25.25 \%$ & $0.66 \%$ & $19.34 \%$ \\
$\mathbf{5}$ & $38.28 \%$ & $4.44 \%$ & $9.00 \%$ & $2.28 \%$ & $24.21 \%$ & $0.25 \%$ & $21.55 \%$ \\
$\mathbf{6}$ & $47.12 \%$ & $5.52 \%$ & $9.05 \%$ & $2.00 \%$ & $20.92 \%$ & $1.06 \%$ & $14.34 \%$ \\
$\mathbf{7}$ & $27.45 \%$ & $2.94 \%$ & $16.67 \%$ & $1.96 \%$ & $29.41 \%$ & $0.00 \%$ & $21.57 \%$ \\
$\mathbf{8}$ & $27.45 \%$ & $2.94 \%$ & $16.67 \%$ & $1.96 \%$ & $29.41 \%$ & $0.00 \%$ & $21.57 \%$ \\
$\mathbf{9}$ & $50.24 \%$ & $5.24 \%$ & $6.95 \%$ & $2.19 \%$ & $20.49 \%$ & $0.49 \%$ & $14.39 \%$ \\
10 & $28.09 \%$ & $3.80 \%$ & $25.37 \%$ & $2.00 \%$ & $30.39 \%$ & $2.58 \%$ & $7.87 \%$ \\
$\mathbf{1 1}$ & $29.81 \%$ & $1.92 \%$ & $4.81 \%$ & $5.00 \%$ & $31.09 \%$ & $0.00 \%$ & $27.37 \%$ \\
$\mathbf{1 2}$ & $15.63 \%$ & $1.00 \%$ & $6.25 \%$ & $3.00 \%$ & $15.00 \%$ & $34.00 \%$ & $25.13 \%$ \\
$\mathbf{1 3}$ & $36.92 \%$ & $1.36 \%$ & $10.08 \%$ & $0.95 \%$ & $23.71 \%$ & $0.27 \%$ & $26.70 \%$ \\
$\mathbf{1 4}$ & $40.37 \%$ & $3.56 \%$ & $17.42 \%$ & $1.72 \%$ & $21.96 \%$ & $0.00 \%$ & $14.97 \%$ \\
$\mathbf{1 5}$ & $55.97 \%$ & $7.55 \%$ & $0.63 \%$ & $0.63 \%$ & $12.58 \%$ & $0.00 \%$ & $22.64 \%$ \\
\hline
\end{tabular}

Table 2. Preference declared.

\begin{tabular}{cccccccccccccccc}
\hline ZONES & $\mathbf{1}$ & $\mathbf{2}$ & $\mathbf{3}$ & $\mathbf{4}$ & $\mathbf{5}$ & $\mathbf{6}$ & $\mathbf{7}$ & $\mathbf{8}$ & $\mathbf{9}$ & $\mathbf{1 0}$ & $\mathbf{1 1}$ & $\mathbf{1 2}$ & $\mathbf{1 3}$ & $\mathbf{1 4}$ & $\mathbf{1 5}$ \\
\hline YES \% & 43 & 44 & 37 & 46 & 47 & 48 & 54 & 54 & 54 & 64 & 44 & 53 & 35 & 50 & 39 \\
NO\% & 57 & 56 & 63 & 54 & 53 & 52 & 46 & 46 & 46 & 36 & 56 & 47 & 65 & 50 & 61 \\
\hline
\end{tabular}


of students would like to use school buses and the other $50 \%$ opt for other modes of transport.

\subsubsection{Supply Approach}

The supply measurement aimed to define the buses occupancy and their number of cycles. We conducted a survey dedicated to 417 bus drivers between June and August in 2016, which comprises questions about the number of students and travel time per cycle bus. $\mathrm{C}$ values represent the range of the index occupancy which one zone is less than $100 \%$. One hundred per cent of occupancy is considered when each school bus carried twenty students (Figure 3 ).

The methodology is based on the determination of the average of number of cycles in each zone. For this proposed, the number of cycles in each bus is determined. Table 3 shows us a result of the average number of cycles in each zone.

\subsection{Model Formulation}

The proposed model uses a mathematical formula for obtaining the optimum number of school buses related to each zone and supply level. The principal assumption is the relation between the number of students to be transported and the bus school capacity. Equation (1)

$$
N v=\sum z_{i}\left(\frac{D_{i}}{S_{i} * I O_{i} * N C_{i}}\right)=\left[\left(\frac{D_{1}}{S_{1} * I O_{1} * N C_{1}}\right)+\left(\frac{D_{2}}{S_{2} * I O_{2} * N C_{2}}\right)+\cdots\right]
$$

where $N_{V}$ is the number of school buses, $Z$ represents the zone index, $D_{i}$ is the number of students ${ }^{\star}$ declared preference, $S_{i}$ is the bus capacity, $I O_{i}$ index occupancy and $N C_{i}$ represents the average of cycles.

The model considers a cycle $\left(N C_{i}\right)$ the dynamic of the student taking the

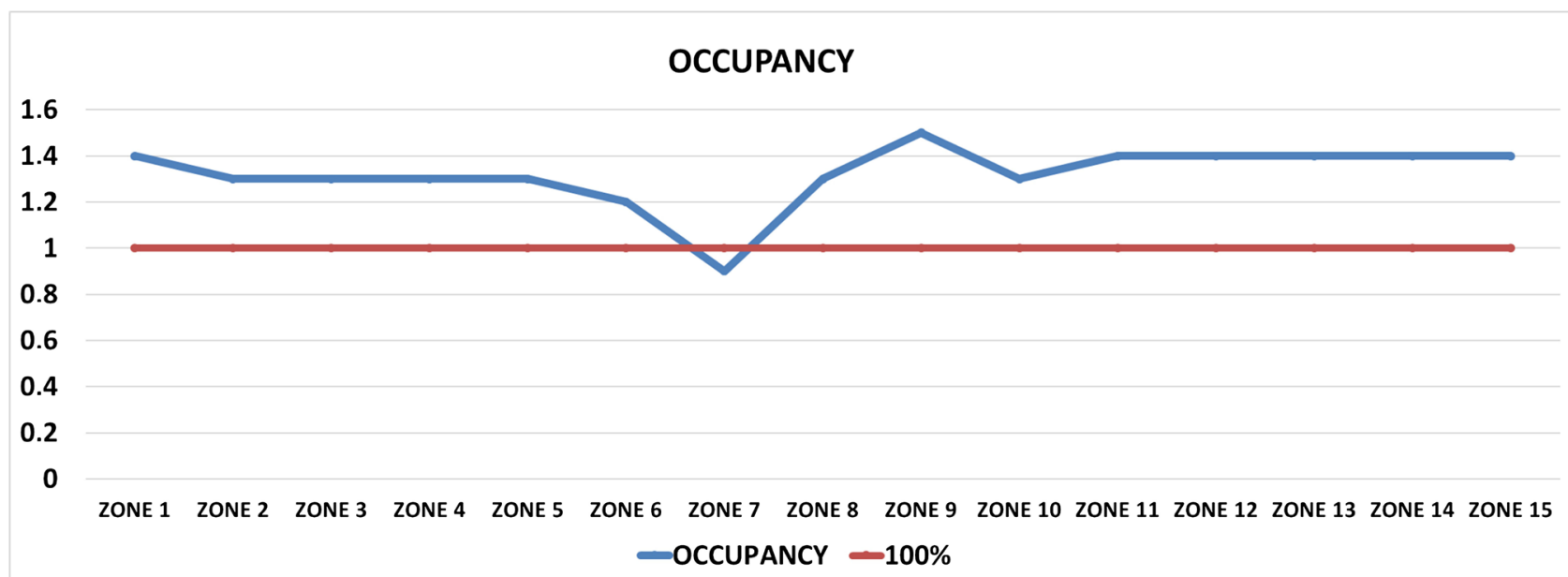

Figure 3. Occupancy per zone.

Table 3. Number of cycles.

\begin{tabular}{cccccccccccccccc}
\hline ZONE & $\mathbf{1}$ & $\mathbf{2}$ & $\mathbf{3}$ & $\mathbf{4}$ & $\mathbf{5}$ & $\mathbf{6}$ & $\mathbf{7}$ & $\mathbf{8}$ & $\mathbf{9}$ & $\mathbf{1 0}$ & $\mathbf{1 1}$ & $\mathbf{1 2}$ & $\mathbf{1 3}$ & $\mathbf{1 4}$ & $\mathbf{1 5}$ \\
\hline CYCLES & 3 & 4 & 4 & 4 & 4 & 4 & 4 & 4 & 4 & 2 & 2 & 4 & 4 & 2 & 4 \\
\hline
\end{tabular}


school transport at a daily time from home to school or from school to home, in our model the number of cycles varies between one to four per bus. The future-demand (number of students * declared preference Equation (2)), who are willingness to use for a bus school is indicated by $D_{i}$, as result, high future-demand for bus school induce to increase of the number of school buses. The opposite may also occur, decreasing demand resulting in a decrease in the number of school buses. The number of buses needed is a function of the number of bus capacity, which has a seating capacity of twenty seats represent by $S_{i}$. The percentage of occupancy $\left(I O_{i}\right)$ is relation between the number of student per bus and bus capacity, in our case the occupancy increases when increasing the number of students. The number of buses is grouped into three scenarios including one above (short-supply) and one below (excess supply) average category supply-demand equilibrium.

\section{Experimental Analysis}

In this section, we present the results obtained by our approach. Firstly, we introduce our results based on three scenarios short supply, excess supply and equilibrium supply. Then, we evaluate our model by the equilibrium graphic.

\subsection{Estimated Results of the STSDR Model}

The problem of the school buses repartition has been solved in Cuenca city using our new mathematical formulation. Table 4 and Figure 4 show the findings of the bus school transport supply measurement using the STSDR model as described above. For example, the number of buses needed within zone number seven was calculated as following:

$$
\begin{aligned}
& D_{i}=(\text { number of students } * \text { declared preference }) / \text { number of surveys } \\
& D_{7}=(642 \times 130) / 241 \\
& D_{7}=346
\end{aligned}
$$

$$
\begin{gathered}
N v=\sum z_{i}\left(\frac{D_{i}}{S_{i} * I O_{i} * N C_{i}}\right) \\
N v_{7}=\left(\frac{346}{20 \times 1 \times 4}\right) \\
\text { Nvneeded }_{7}=4 \\
\text { Nvbefore }_{7}=5 \\
\text { Results }=^{\text {Nvneeded }} \text { - } \text { Nvbefor }_{7}=-1
\end{gathered}
$$

We introduce our results on three scenarios:

1) Short supply is provided for seven zones $(2,6,9,11,12,14$ and 15) including 30,514 of 75,000 students, which are considered future-demand.

2) The opposite scenario has been called excess supply or lack of demand in 
which there are seven zones $(1,3,4,7,8,10$ and 13) with 42,272 students where the number of buses is more than the future-demand as seen in Table 4.

3) The Supply-demand equilibrium is applied only in zone 5, where all the factors (i.e. future-demand, bus capacity, index occupancy and the number of cycles) are in balance and not leading to further change.

\subsection{Evaluation of Our Proposed Model Formulation}

We evaluate our model formulation using two supply-demand graphs, which reproduce the supply-demand behavior in Cuenca city based on 417 school buses distributed in 15 zones with 75,000 students as seen in Figure 5. Figure 5 illustrates the negative relationships between the number of students and the number of school buses in Cuenca city before applying our model. Figure 6 represents the optimum repartition of school buses in each zone in Cuenca city based on our mathematical formulation with an accuracy of $96 \%$.

Table 4. Number of buses in Cuenca city.

\begin{tabular}{|c|c|c|c|c|c|c|c|c|c|c|c|c|c|c|c|}
\hline ZONES & 1 & 2 & 3 & 4 & 5 & 6 & 7 & 8 & 9 & 10 & 11 & 12 & 13 & 14 & 15 \\
\hline N. VEHICLES BEFORE & 50 & 14 & 51 & 22 & 13 & 20 & 5 & 28 & 30 & 105 & 1 & 10 & 18 & 49 & 1 \\
\hline RESULTS & -2 & 3 & -1 & -9 & 0 & 2 & -1 & -11 & 8 & -3 & 2 & 9 & -7 & 1 & 2 \\
\hline N. VEHICLES NEEDED & 48 & 17 & 50 & 13 & 13 & 22 & 4 & 17 & 38 & 102 & 3 & 19 & 11 & 50 & 3 \\
\hline
\end{tabular}

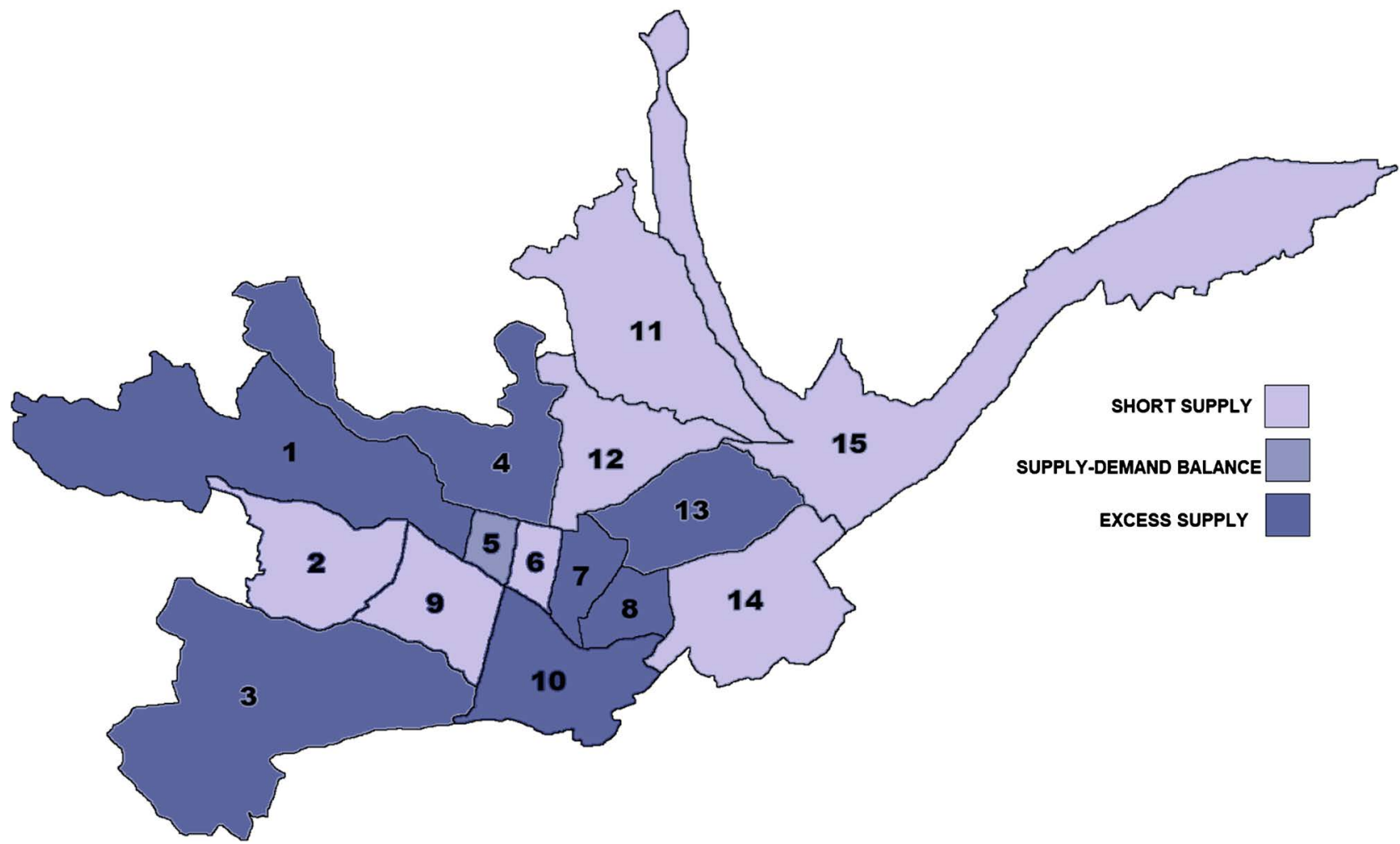

Figure 4. Scenarios of school transportation. 


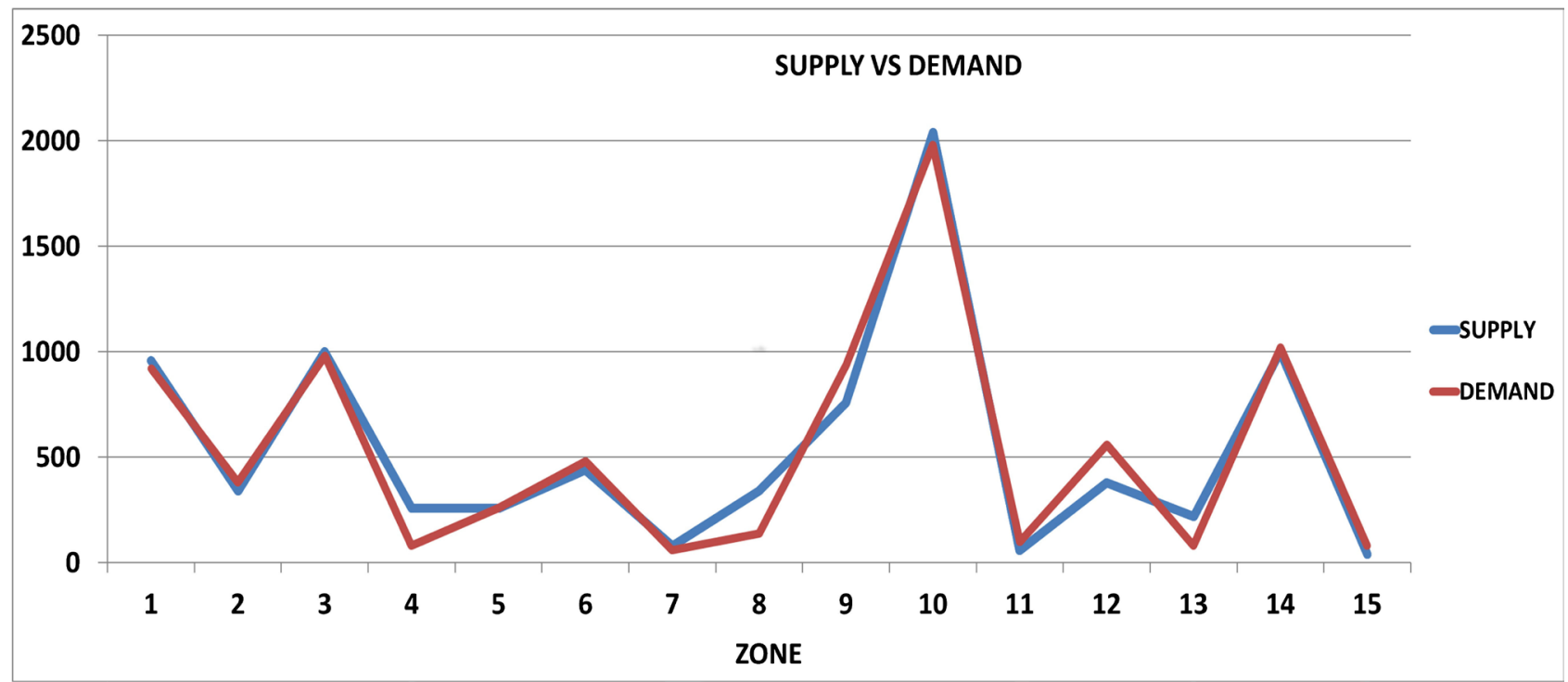

Figure 5. Graph evaluation supply-demand.

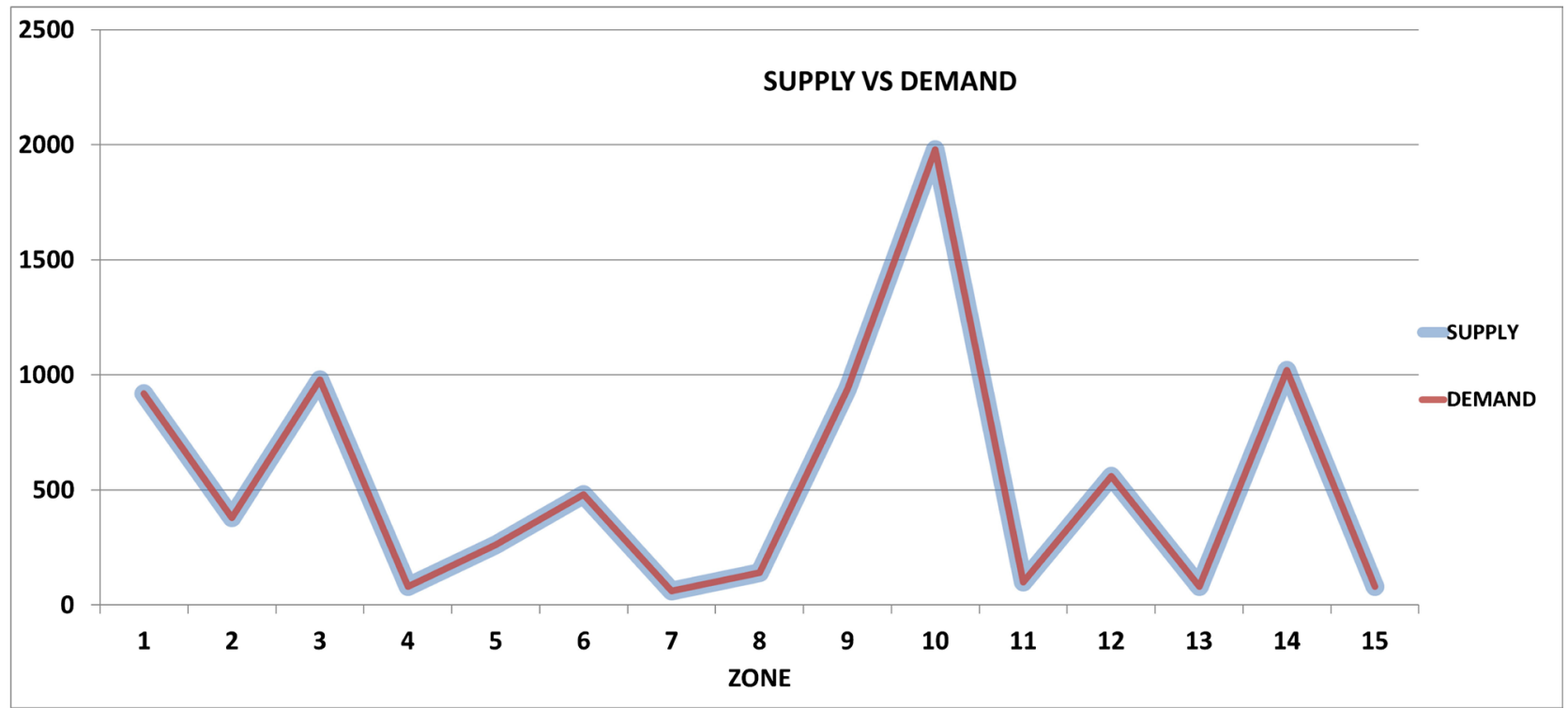

Figure 6. Graph evaluation supply-demand application STSDR.

\section{Conclusion}

This paper has developed a new model of school transportation supply-demand ratio (STSDR) for calculating the number of buses needed within a limited area, from a model formulation and a linking between administrative and survey data. This applied methodology resolves two main problems: 1) to identify and to theorize the causal relationship between administrative and survey data and, 2) to repartition school buses within a limited area.

The STSDR has been applied to Cuenca city (Equator) where there are 15 zones, 600 schools, with a total of 75,514 students. This model has provided three scenarios: short supply, excess supply and equilibrium supply, where four variables are known: 1) number of students * declared preference, 2) bus capaci- 
ty, 3) index occupancy; and 4) average of cycles.

The results obtained to improve the buses distribution have reached an accuracy of $96 \%$. Therefore, future research can make use of this model to further the current understanding of school transportation behavior. This understanding, in due course, will help the development of interventions focused on student's mobility and will contribute towards the development of methodologies in the years to come.

\section{Acknowledgements}

The authors would like to thank Rodrigo Moreno and Juan Jose Carrasco for his technical support and assistance with this project. This research was supported by The Budapest University of Technology and Economics, Hungary.

\section{Conflicts of Interest}

The authors declare no conflicts of interest regarding the publication of this paper.

\section{References}

[1] Rodrigue, J.-P. (2017) The Geography of Transport System. Routledge, New York, 440.

[2] Ibeas, A., Moura, J.L. and dell'Olio, L. (2009) Planning School Transport: Design of Routes with Flexible School Opening Times. Transportation Planning and Technology, 32, 527-544. https://doi.org/10.1080/03081060903374734

[3] Florian, M. and Gaudry, M. (1980) A Conceptual Framework for the Supply Side in Transportation Systems. Transportation Research Part B: Methodological, 14, 1-8. https://doi.org/10.1016/0191-2615(80)90029-6

[4] De Witte, A., Macharis, C., Lannoy, P., Polain, C., Steenberghen, T. and Van de Walle, S. (2006) The Impact of "Free" Public Transport: The Case of Brussels. Transportation Research Part A: Policy and Practice, 40, 671-189. https://doi.org/10.1016/j.tra.2005.12.008

[5] Spada, M., Bierlaire, M. and Liebling, T.M. (2005) Decision-Aiding Methodology for the School Bus Routing and Scheduling Problem. Transportation Science, 39, 443-556. https://doi.org/10.1287/trsc.1040.0096

[6] Schlossberg, M., Greene, J., Phillips, P.P., Johnson, B. and Parker, B. (2006) School Trips: Effects of Urban Form and Distance on Travel Mode. Journal of the American Planning Association, 72, 337-346. https://doi.org/10.1080/01944360608976755

[7] Newton, R.M. and Thomas, W.H. (1974) Bus Routing in a Multi-School System. Computers \& Operations Research, 1, 213-222. https://doi.org/10.1016/0305-0548(74)90047-1

[8] Ezquerro Eguizábal, S., Moura Berodia, J.L., Ibeas Portilla, Á. and Benavente Ponce, J. (2018) Optimization Model for School Transportation Design Based on Economic And Social Efficiency. Transport Policy, 67, 93-101.

[9] Wu, C., Pei, Y. and Gao, J. (2015) Model for Estimation Urban Transportation Supply-Demand Ratio. Mathematical Problems in Engineering, 2015, Article ID: 502739. https://doi.org/10.1155/2015/502739

[10] Dusa, A., Nelie, D., Stock, G. and Wagner, G. (2014) Administrative Data: Problems 
and Benefits. A Perpective from the United Kingdom. Facing the Future: European Research Infrastructure for the Humanities and Social Sciences.

[11] O’Hara, A., Shattuck, R.M. and Goerge, R.M. (2016) Linking Federal Surveys with Administrative Data to Improve Research on Families. The Annals of the American Academy of Political and Social Science, 669, 63-74. https://doi.org/10.1177/0002716216678391

[12] Sakshaug, J.W., Couper, M.P., Ofstedal, M.B. and Weir, D.R. (2012) Linking Survey and Administrative Records: Mechanisms of Consent. Sociological Methods \& Research, 41, 535-569. https://doi.org/10.1177/0049124112460381 